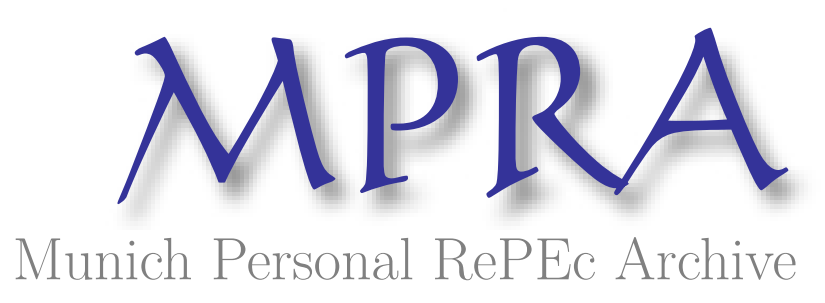

\title{
Local government responsiveness to federal transfers: theory and evidence
}

Rizzo, Leonzio

University of Ferrara

June 2006

Online at https://mpra.ub.uni-muenchen.de/5373/

MPRA Paper No. 5373, posted 19 Oct 2007 UTC 


\title{
Local Government Responsiveness to Federal Transfers: Theory and Evidence
}

\author{
Leonzio Rizzo* \\ University of Ferrara, Department of Economics \\ Via Voltapaletto 11, Ferrara, Italy \\ leonzio.rizzo@unife.it
}

21 June 2006

\begin{abstract}
Federal transfers can depend on local fiscal capacity which is measured by local tax bases. The aim of this paper is to understand to what extent and how these transfers affect local tax decisions. We develop a model with two provinces producing one mobile good. The good is taxed according to the destination principle. Final consumers decide to buy the good from the province where it is cheaper. The two provinces engage in tax competition. The introduction of scale economies into the shopping technology generates nonlinear tax reaction functions which make it possible to test the effect of a transfer equalizing local tax bases on tax competition in two complementary tax regimes. Used for this purpose are cigarette and gasoline tax data from Canada. In the case of cigarette tax it is found that nonlinearity in tax competition is almost entirely offset when equalization holds: tax competition in the two tax regimes become closer. The shopping technology for gasoline gives less scope for scale economies, so that equalization does not affect reaction functions.
\end{abstract}

Keywords: fiscal competition, equalization, transfer, externality, taxrate.

JEL classification: H21, H23.

${ }^{*}$ This work was developed during my EU Marie Curie fellowship at STICERD, London School of Economics. I wish to thank Tim Besley for his constant encouragement, comments and advices. I also thank the editor Jay Wilson, three anonymous referees, Oriana Bandiera, Roberto Censolo, Umberto Galmarini, Valentino Larcinese, Ben Lockwood, Robert MacCulloch, Giovanni Ponti, Imran Rasul, Michael Smart, Cecilia Testa, Myrna Wooders and all those who attended seminars at the University of Ferrara, IFS, at the Catholic University of Milan, Warwick University, Lausanne, LSE, University of Bari, University of Malaga, UCLA Los Angeles 2002, University Paris-1 Pantheon-Sorbonne, for helpful comments. The usual disclaimer applies. This is a previous version of the forthcoming in the International Tax and Public Finance (http://www.springerlink.com/content/k66872u452412810/) 


\section{Introduction}

In federal countries, such as Canada or the USA, indirect taxes are often autonomously decided by each province or state, and people are able to cross borders freely and buy goods at the better price.

In this situation each state typically fixes its tax rate without taking account of the benefits in revenue and/or social welfare accruing from its tax-base migration to the other state (Mintz and Tulkens 1986; Kanbur and Keen 1993). As a consequence the equilibrium tax rate tends to be inefficiently low or high (Wooders et al., 2002).

Transfers are usually needed to mitigate these inefficiencies by compensating for the loss in revenue due to mobility. Are such transfers important from a practical point of view? Do they affect local states' fiscal policies?

This is a key issue within the European Union, where mobility relates to the elimination of fiscal borders and the implementation of the origin VAT system. Approval of a clearing compensation mechanism (Commission, 1985) would ensure that each nation obtains the same revenue as in a destination system. It therefore should eliminate the incentive for each nation to use its taxes strategically.

To address these important issues we study an interesting empirical situation represented by the Canadian equalizing transfer system. This paper tests the responsiveness - through local tax decisions - of Canadian provinces to the equalizing transfer coming from the federal government. Given 33 tax bases, the transfer is computed by summing up the difference between a province's tax base and a standard tax base, using a standard equalization rate for this purpose. If the sum is positive no transfer is awarded; if it is negative, the corresponding equalization transfer is made. In the former case we have a world without transfers, in the latter a world with transfers. When tax bases are mobile this transfer works exactly as a compensating mechanism for the lost tax base.

According to our theoretical model, the reason for tax-base mobility is that tax differentials may encourage cross-border shopping from the low-tax to the high-tax province. Goods in low-tax jurisdictions are transported, stored and consumed into high tax jurisdictions; moreover; in the case of illegal cross-border shopping (Thursby and Thursby, 2000) counterfeit stamps are used so that the goods can be sold. Significant price differentials between jurisdictions create incentives for cross-border shopping. As a consequence, a change in tax by one jurisdiction affects the tax base of the other jurisdiction (horizontal externality) by inducing it to change its tax. This process generates the reaction function which relates the own tax rate to the other jurisdiction's tax rate. We show that when the reaction functions are not linear because the good is easily storable, the introduction of an equalization transfer changes their slopes.

The change in the slope of the reaction function is tested by using tax rates on cigarettes and gasoline in a panel-data study at province level for Canada 
during the period 1984-1994. We find that the cigarette tax reaction function is nonlinear. In the theory, the nonlinearity comes from scale economies in the cross-border shopping technology. The equalization transfer affects cigarettes reaction functions by almost entirely offsetting their nonlinearity. The gasoline tax reaction function is instead linear (it is not easy to buy gasoline in low tax jurisdictions and transport and store it in high tax jurisdictions), so that equalization does not affect its functional form.

The paper is organized as follows. Section 2 examines the literature. Section 3 develops the theoretical model and Section 4 describes the effect of the transfer on the reaction function. Section 5 resumes the testable hypotheses and Section 6 presents the empirical analysis. Finally Section 7 concludes.

\section{Related literature}

The source of the tax externality between neighboring provinces relates to the distribution of potential taxpayers between provinces and to the cost of shopping in the other province. Both determinants are reflected by the slope of each province's tax reaction. Scharf (1999) introduces a fixed transaction cost of shopping and a storage cost, together with a linear transport cost to the border. This generates a cross-border shopping cost function concave in the distance from the border which affects the tax externality and the slope of the provinces' reaction function. Devereux, Lockwood and Redoano (2001) model corporate tax competition with a spatial model à la Hotelling. They assume that each investor is subject to a linear cost function if she does not invest in her province. In their case, the change in the slope of the provinces' reaction function is due to the investor distribution in each province, which is assumed to be single-peaked. These nonlinearities are very interesting from an empirical point of view because their estimation enables the interpretation of the tax link between neighboring provinces due to tax competition. Brett and Pinkse (1997, 2000) empirically assess this issue using Canadian data from municipalities in British Columbia. They estimate a structural tax base equation, not finding a significant coefficient of the neighboring taxes; but, they find a significant link between neighboring taxes and a given municipal tax. Interestingly, they conclude that the relation is not due to tax competition, but to some other factor like yardstick competition. Another interesting idea is put forward by Heyndels and Vuchelen (1998), who analyze the source of the spatial pattern of Belgian municipalities by discriminating between first order and second order neighbors, depending on whether they have a border in common. In the former case, these are municipalities with a boundary in common with a given municipality; in the latter, they are municipalities with a boundary in common with the first order neighbors. Heyndels and Vuchelen test yardstick competition for local income tax and local property tax, finding a significant coefficient for both neighbors, with a value stronger for first order 
than for second order neighbors: municipalities sharing borders with immediate neighbors exert an influence on tax choices which decreases with geographical distance.

Various theoretical studies have discussed the effects of equalization on taxes. With regards to situations without tax base mobility, Smart (1998) uses an optimal taxation model to study the effect of the Canadian equalization system, showing that equalization induces a substitution effect that lowers the effective marginal cost of public funds. The transfer reduces the taxation burden on local taxpayers. If the revenue effect is not very high, equalization induces an increase in the equilibrium tax rate which results in an inefficiently high level of taxation. This idea is also explored in Kothenburgen (2002), who uses a model where a private good is produced through a production function with capital and labor. Local taxes on capital finance the provision of the local public good and capital is mobile. In a symmetric environment, where all provinces have the same population and endowments, the Canadian equalization system implements the optimal choice that would be made by a unitary government. Taxes, which are too low in a symmetric Nash equilibrium, increase with equalization. The increase in tax rate reduces the marginal cost of public funds because a lower amount of tax base is lost due to an increase in tax. If provinces are symmetric in equilibrium there is no revenue effect because there is no transfer between them, that would induce the recipient province to reduce its tax. Bucovetsky and Smart (2006) show that the equalization system - with some "ad hoc" corrections - guarantees the optimal solution even when allowing for asymmetric countries in the productivity of capital or in the population ${ }^{1}$.

There are few recent papers on the effects of transfers on tax-reaction functions. Boadway and Hayashi (2001) use Canadian annual data 1963-1996 to test horizontal and fiscal interactions, where each estimate is for a single province or an average province. They find that Ontario's average tax on capital has a significant impact on Quebec's, but that the reverse does not hold. Boadway and Hayashi explain this by the equalization system: Ontario is a non-recipient province and Quebec is a recipient province. Esteller-Moré, Sollé-Ollé (2002) test fiscal interactions and the effect of equalization on the average personal income tax, using a Canadian panel data-set 1982-1996. They find significant horizontal and vertical tax interactions and a significant effect of equalization on the reaction function, but they do not give theoretical explanation as to why the introduction of equalization should exert the particular negative effect on the reaction function slope.

This paper uses a Canada-US panel data set (1984-1994) and estimates tax competition for cigarettes and gasoline in Canada using a nonlinear model. It examines the effects of equalization by checking the change in the nonlinearity of the reaction function envisaged by the theory. If the tax-reaction function slope

\footnotetext{
${ }^{1}$ In the latter case the equalization formula must be corrected by a parameter depending on the elasticities of supply and demand.
} 
is constant as in Kanbur and Keen (1993), it is easy to show that it is unaffected by the equalizing transfer, as it happens for gasoline in Canada.

\section{The model}

Consider a federation with two member provinces with equal populations, normalized to 1 and uniformly distributed. One mobile good is produced by using one input with a constant returns to scale technology. When the destination principle (people pay tax where they consume the good) holds, cross-border shopping may occur legally or illegally. In the former case the good is legally transported from the low tax province to the high tax province for own consumption, while in the latter case it is normally resold. This latter phenomenon is also known as bootlegging.

Let $i=1,2$ index the two provinces. Both have the same number of residents. One province is located at $[-1,0]$ and the other at $[0,1]$. Since the residents are uniformly distributed, the distance of each resident from the border is $d \in[0,1]$. Define $r$ as the resident's reservation price, net of the production cost, identical in both provinces. If $r$ is nonnegative the resident demands one unit of the good; otherwise she will demand zero. One can imagine that each resident consumes an identical amount of the produced good. To simplify the analysis, we normalize the quantity consumed by each resident to 1 . The following assumption is useful:

Assumption 1: The cost of cross-border shopping the normalized demanded quantity for a consumer situated at a distance $d$ from the border is:

$$
\phi(d)=\frac{\ln (1+d)}{A} .
$$

where $A \geq 1$ is a fixed parameter. Note that $\phi(d)$ is an increasing and concave function and at $\phi(0)=0$. When $A \rightarrow \infty$, we have the perfect mobility case; in fact $\phi(d)=0 \forall d . A=1$ implies $\phi(d)=\ln (1+d)$. Moreover, since $0 \leq d \leq 1$, then $0 \leq \phi(d) \leq \frac{\ln 2}{A}$. Assumption 1 accounts for the possibility to store the good and thereby save on the fixed transaction cost involved in the cross-border shopping activity $^{2}$ (Scharf, 1999; Asplund et al., 2005).

We also assume the following:

\footnotetext{
${ }^{2}$ The cost of cross-border shopping results from a variable cost of shopping depending on the distance from the border (transport cost) and a fixed transaction cost for each trip and a storage cost (Scharf, 1999). Shoppers decide the optimal number of trips necessary to satisfy their demand by comparing the sum of the transport and transaction cost with the storage cost: the farther the consumer is from the border, the lower the optimal number of trips and the greater the amount of the good purchased in every trip. Therefore if the distance from the border increases, the transport cost increases, the total fixed transaction cost decreases and the storage cost increases. A concave storage cost ensures concavity of the cross-border shopping cost over the distance from the border. In a stylized model such as the one presented here, this reasoning can be summarized as a cost of cross-border shopping concave in the distance from the border.
} 
Assumption 2: $r<\frac{1}{A}$.

The greater $\mathrm{A}$ is, the smaller the cross-border shopping cost for a given distance from the border. Since A measures the advantage the consumer may obtain from shopping in the border market, given her distance from the border, it seems reasonable to assume that the upper bound of the customer's reservation price (the willingness to pay) for the good sold inside her province depends negatively on $\mathrm{A}$.

Assumption 2 is necessary and sufficient to guarantee in equilibrium positive reaction functions in the no-equalization case. ${ }^{3}$

\subsection{The consumer decision}

Let $t_{i} \in[0, r]$ be the specific unit tax on the mobile good, levied by province $i$. Assume that $t_{1}>t_{2}$. The consumer in province 1 decides where to buy the good according to her net surplus. If the customer buys in province 1 , she pays $t_{1}$ plus the production cost. If the customer purchases bootlegged goods from province 2 , she pays $\phi(k)+t_{2}$ plus the production cost, where $k$ is the distance from the border of the consumer in province 1, who is indifferent between shopping in province 2 or in province 1 . Therefore consumer in province 1 will shop from province 2 until:

$$
r-\left[\phi(k)+t_{2}\right]=r-t_{1}
$$

If we use (1):

$$
k=\left[\phi\left(t_{1}-t_{2}\right)\right]^{-1}=e^{A\left(t_{1}-t_{2}\right)}-1 .
$$

Since consumers in province 1 are uniformly distributed on $[0,1], k$ is also the number of residents in province 1 , buying goods from province 2 , for a given $t_{1}-t_{2}$. Note that the larger $t_{1}$, the bigger the increase in the number of people shopping from province 2 , for a given increase in $t_{1}\left(\frac{d k}{d t_{1}}>0\right.$ and $\left.\frac{d^{2} k}{d t_{1}^{2}}>0\right)$. This is because the higher $t_{1}$, the farther from the border the indifferent consumer is, the lower the increase in cross-border shopping cost $\left(\phi(d)^{\prime \prime}<0\right){ }^{4}$

If $t_{1} \leq t_{2}$, analogously we obtain:

$$
l=e^{A\left(t_{2}-t_{1}\right)}-1,
$$

\footnotetext{
${ }^{3}$ The proof is available upon request.

${ }^{4}$ Fitz Gerald et al.(1995) analyze two case-studies: Germany-Denmark and Ireland-Northern Ireland. In both cases the greater the distance from the border, the larger the amount of goods purchased and the fewer the trips made in any given period. Interestingly Asplund et al. (2005) find a "striking upward sloping relation between the distance from the border and the growth in sales" in a study on spirits sales across the Sweden-Denmark border. They also argue that "these products are easily transportable and storable".
} 
where $l$ is the distance from the border of the consumer in province 2, who is indifferent between shopping in province 2 or from province $1 . l$ is also the number of residents in province 2 , buying goods from province 1 , for a given $t_{1}-t_{2}$.

Finally, if $t_{1}>t_{2}$ :

$$
B_{1}=1-k\left(t_{1}, t_{2}\right)
$$

and if $t_{1} \leq t_{2}$ :

$$
B_{1}=1+l\left(t_{1}, t_{2}\right),
$$

where $B_{1}$ is the tax base faced by province 1 , whose population is normalized to 1. We can simplify notation by defining:

$$
n\left(t_{1}, t_{2}\right)= \begin{cases}-k\left(t_{1}, t_{2}\right) & \text { if } t_{1}>t_{2} \\ l\left(t_{1}, t_{2}\right) & \text { if } t_{1} \leq t_{2} .\end{cases}
$$

Substituting (6) in (4) or (5):

$$
B_{1}=1+n\left(t_{1}, t_{2}\right)
$$

implying:

$$
B_{2}=1-n\left(t_{1}, t_{2}\right)
$$

where $n$ is the incoming or outgoing mobile tax-base quota depending on which tax regime we are dealing with.

\subsection{The province problem}

We assume that the following transfer holds for province $i$ :

$$
T_{i}=\alpha\left(1-B_{i}\right),
$$

where $\alpha$ is the equalization rate, and the standard mobile tax base, equal to 1 , coincides with the average tax base of the federation. We make the following assumption on the equalization rate:

Assumption 3: $\alpha<\frac{1}{A}$.

Assumptions 1, 2 and 3 are sufficient to have positive reaction functions and to show the existence of tax-rates Nash equilibrium in the equalization case. ${ }^{5}$

Note that, by (7)-(9), $T_{1}+T_{2}=\alpha\left(1-B_{1}\right)+\alpha\left(1-B_{2}\right)=\alpha(-n+n)=0$.

Both provinces know the resident's behavior described in the previous section and simultaneously choose their respective $t_{i}$, by maximizing the following function:

$$
W_{i}=B_{i} t_{i}+T_{i}-\gamma_{i} t_{i}
$$

\footnotetext{
${ }^{5}$ Proof available upon request.
} 
using (9):

$$
W_{i}=B_{i} t_{i}+\alpha\left(1-B_{i}\right)-\gamma_{i} t_{i},
$$

where $B_{i}$ is the tax base of province $i$, given by (7) or (8); $0 \leq \gamma_{i} \leq 1$ accounts for the increase in unpopularity after a unit increase in $\operatorname{tax}^{6}$ in province $i$. Moreover $\gamma_{1} \neq \gamma_{2}$. This last inequality is useful in that it rules out symmetric equilibria which would prevent any comparative statics, because the derivative with respect to $t_{i}$ of the FOC of (10) does not exist in $t_{1}=t_{2}$.

\section{The reaction function slope}

If we put $i=1$ in (11) and substitute (7) in (11) we obtain:

$$
W_{1}=t_{1}\left(1+n\left(t_{1}, t_{2}\right)\right)-\alpha n\left(t_{1}, t_{2}\right)-\gamma_{1} t_{1} .
$$

The equalizing transfer affects the tax-rate choice by entering into the objective function. Province 1 receives (or gives) the compensation transfer $\alpha n$ (recall that $n$ is the mobile tax-base quota from province 1 to province 2 ) if a quota of its tax base shifts into (or out of) the other province.

Province 1 chooses $t_{1}$, which maximizes (12), obtaining the following first order condition:

$$
\frac{d W_{1}}{d t_{1}}=\left[(1+n)+\left(t_{1}-\alpha\right) \frac{d n}{d t_{1}}\right]-\gamma_{1}=0
$$

We totally differentiate (13), and by using (1), (2) and (6) get the slope of the tax-rate reaction function if $t_{1}>t_{2}$ :

$$
\left.\frac{d t_{1}}{d t_{2}}\right|_{t_{1}>t_{2}}=\frac{1+A\left(t_{1}-\alpha\right)}{2+A\left(t_{1}-\alpha\right)} .
$$

We do the same for $t_{1}<t_{2}$ and by using (1), (3), (6):

$$
\left.\frac{d t_{1}}{d t_{2}}\right|_{t_{1}<t_{2}}=\frac{1-A\left(t_{1}-\alpha\right)}{2-A\left(t_{1}-\alpha\right)} .
$$

If Assumptions 1, 2 and 3 hold, (14) and (15) are both positive. If Assumption 3 does not hold the high tax province could not have the incentive to positively react to an increase in tax by the other province. An increase in $t_{2}$ decreases the migrating tax-base quota, for a given $t_{1}$, if $t_{1}>t_{2}$, or increases it, for a given $t_{1}$, if $t_{1}<t_{2}:^{7}$ in both cases province 1 increases $t_{1}$. With more general models this

\footnotetext{
${ }^{6}$ This term is endogenously derived in the yardstick competition literature (Besley, Case 1995). Here we do not model yardstick competition but only take into account its effect in a static context.

${ }^{7}$ Henceforth we do not deal with the case $t_{1}=t_{2}$ because, given that $\gamma_{1} \neq \gamma_{2}$, the tax-rates Nash equilibrium is asymmetric.
} 
result could not hold. For example in the standard Zodrow-Mieszkowsky (1986) model of tax competition, reaction curves may slope up or down.

Note that as the difference in provincial tax rates grows, the marginal consumer crossing the border resides farther from the border, where costs are less sensitive to distance at the margin, and therefore the number of individuals choosing to be cross-border shoppers is more sensitive to the tax difference. It follows that if, $t_{1}>t_{2}$ initially, then a rise in $t_{2}$ reduces the difference in provincial taxes and hence the marginal sensitivity of the number of cross-border shoppers to $t_{1}$, thereby providing more of an incentive to raise $t_{1}$. On the other hand, if $t_{1}<t_{2}$ initially, then a rise in $t_{2}$ increases the difference in provincial taxes and hence the marginal sensitivity, thereby providing incentives not to raise $t_{1}$ as much. Interestingly, given that $t_{1}>\alpha^{8}$, we can establish that when $t_{1}>t_{2}$ :

$$
\frac{d t_{1}}{d t_{2}}=\frac{1+A\left(t_{1}-\alpha\right)}{2+A\left(t_{1}-\alpha\right)}>\frac{1}{2}
$$

and when $t_{1}<t_{2}$ :

$$
\frac{d t_{1}}{d t_{2}}=\frac{1-A\left(t_{1}-\alpha\right)}{2-A\left(t_{1}-\alpha\right)}<\frac{1}{2},
$$

that is to say, that the slope of the reaction function when $t_{1}>t_{2}$ is steeper than when $t_{1}<t_{2}$.

\subsection{The effect of the transfer}

An equalizing transfer changes the incentive to raise $t_{1}$ after an increase in $t_{2}$. In fact, if $t_{1}>t_{2}$ initially, equalization can offset the effect of the rise in $t_{2}$ on the marginal sensitivity of the number of cross-border shoppers to $t_{1}$. This is because introducing equalization has the same effect on the provincial revenue as decreasing the number of cross-border shoppers. It follows that a rise in $t_{2}$, even reducing the difference in provincial taxes, reduces less than before the marginal sensitivity of the number of cross-border shoppers to $t_{1}$, thereby decreasing the incentive to raise $t_{1}$. On the other hand, if $t_{1}<t_{2}$ initially, then a rise in $t_{2}$ increases to a lesser extent the marginal sensitivity of the number of crossborder shoppers, thereby increasing the incentive to raise $t_{1}$. This operates in the opposite direction to the process determining the previous difference in slope, and therefore decreases it. Hence, the difference in slopes of the tax-rate reaction functions of a province receiving the equalization transfer, between the case $t_{1}>t_{2}$ and the case $t_{1}<t_{2}$, is smaller than the corresponding difference in the noequalization case, namely:

$$
\left.\left[\left.\frac{d t_{1}}{d t_{2}}\right|_{t_{1}>t_{2}}-\left.\frac{d t_{1}}{d t_{2}}\right|_{t_{1}<t_{2}}\right]\right|_{\alpha>0}<\left.\left[\left.\frac{d t_{1}}{d t_{2}}\right|_{t_{1}>t_{2}}-\left.\frac{d t_{1}}{d t_{2}}\right|_{t_{1}<t_{2}}\right]\right|_{\alpha=0} .
$$

\footnotetext{
${ }^{8}$ Otherwise (13) does not hold. In fact when $t_{1}<t_{2},(1+n)-\gamma_{1}>0$ and in both tax regimes $\frac{d n}{d t_{1}}<0$. It follows that if $t_{1}$ is bigger, namely $t_{1}>t_{2}, t_{1}>\alpha$ must also hold.
} 
The above relationship (see appendix for the proof) holds if the introduction of the transfer will not increase the tax rate more than the equalization rate. That is to say, $\frac{d t_{1}}{d \alpha}<1$, which, given Assumption 1, is guaranteed by reasonable Assumptions on the reservation price and equalization rate (Assumption 2 and 3), ensuring the existence of Nash equilibrium tax rates. ${ }^{9}$

\section{Testable hypotheses}

We test the following hypotheses:

$$
\begin{aligned}
& \text { H1. } \frac{d t_{1}}{d t_{2}}>0 \\
& \text { H2. }\left.\frac{d t_{1}}{d t_{2}}\right|_{t_{1}>t_{2}}-\left.\frac{d t_{1}}{d t_{2}}\right|_{t_{1}<t_{2}}>0 \quad \forall \alpha\left[0, \frac{1}{A}[\right. \\
& \text { H3. }\left.\left[\left.\frac{d t_{1}}{d t_{2}}\right|_{t_{1}>t_{2}}-\left.\frac{d t_{1}}{d t_{2}}\right|_{t_{1}<t_{2}}\right]\right|_{\alpha>0}>\left.\left[\left.\frac{d t_{1}}{d t_{2}}\right|_{t_{1}>t_{2}}-\left.\frac{d t_{1}}{d t_{2}}\right|_{t_{1}<t_{2}}\right]\right|_{\alpha=0}
\end{aligned}
$$

Assumption 1 on the shape of the bootlegging cost function is of course indirectly tested by verifying its effect on the reaction function slope (Hypothesis 2). ${ }^{10}$ The test on $\mathrm{H} 2$ makes sense if Hypothesis 1 is verified. Thereafter, we test whether the difference in slopes is affected by the existence of the equalization transfer (Hypothesis 3).

\section{The empirical test}

We estimate the tax-reaction function for cigarette and gasoline relating one provinces' tax to its neighbor's tax in two different situations: a province in a federation with a transfer mechanism like the one outlined in the previous section; a province with no transfer mechanism. We find both situations in Canada, where there is an equalization system but not all provinces get it.

The Canadian equalization transfer is computed by using 33 tax bases. Equalization entitlements are computed for each of the 33 separate revenue categories. A jurisdictions's per-capita entitlement in a revenue category is equal to its percapita tax-base deficiency in the category relative to a standard multiplied by the national average tax-rate for the category. ${ }^{11}$ Equalization entitlements are summed over all revenue categories: jurisdictions with a positive total entitlement receive a transfer of that amount from the federal government, whereas

\footnotetext{
${ }^{9}$ The proof on the existence of the equilibrium is available upon request.

${ }^{10} \mathrm{As}$ far as we know, there is only one study from Asplund et al. (2005) which "more directly" tests this assumption, finding evidence in the case of Sweden-Denmark border of a positive relationship between the distance from the border and the quantity of spirits sold from the low tax nation (Denmark) to cross-border consumers.

${ }^{11}$ The standard is the average per-capita tax base of five provinces: Quebec, Ontario, Manitoba, Saskatchewan and British Columbia.
} 
jurisdictions with a negative total entitlement receive no transfer. Therefore the provinces that receive the transfer are the only ones affected by the equalization system.

We split the Canadian provinces ${ }^{12}$ during 1984-1994 into those whose budget constraints were not affected by the equalization formula (Alberta, Ontario, British Columbia and - only for the period 1984-85 - Saskatchewan) and those whose budget constraints were affected (Newfoundland, Prince Edward Island, Nova Scotia, New Brunswick, Quebec, Manitoba and - only for the period 198694 - Saskatchewan). The former group comprised 35 observations and the latter group 75 observations.

To isolate the independent impact of neighboring tax rates on the tax rate of a Canadian province, other variables that might affect the provincial tax rate are taken into account. First, we control for the US neighboring tax rates. Moreover, the province's tax rate on commodities depends on several other types of variable. Provincial taxation may be influenced by the economic and demographic environment. This is controlled by using the following variables: population, density, per-capita income, per-capita GDP, unemployment rate, proportion of population over 65, total expenditure over GDP. Account is taken of the federal fiscal instruments, which may differ from province to province, by using federal grants-in-aid in relation to total population and the federal income tax, collected in each province, normalized with GDP. For the previous variables we computed the corresponding mean variables of the neighboring Canadian provinces and neighboring US states to each Canadian province.

The political affiliation of the provincial government may also affect the taxrate level: we divide the Canadian party system in three main groups: ProgressiveConservative, which is right wing; Liberal, which is center; and a left wing group composed of the New Democratic Party, the Parti Québecois and the Social Credit Party. We then build dummies for the provincial premier's membership in each of the three groups and variables accounting for the percentage in the legislature of the three political groups.

There are certain unchanging characteristics of a province that are likely to affect its fiscal system, such as climate and geography. We take these characteristics into account by including a dichotomous variable for each province.

Changes in the macroeconomic situation may affect the fiscal policies of all provinces. To account for this, we use a dichotomous variable for each year. These effects are very important in the present context because the years 1984-94 saw an increasingly severe federal no-smoking policy which led to massive increases in the tax rate on cigarettes. This was followed by a very large increase in cigarette exports year by year.

\footnotetext{
${ }^{12}$ We excluded the three Territories Nunavut, Nortwest Territories and Yukon because they represent a very small part of Canada in terms of population, income and tax base.
} 


\subsection{Hypotheses}

The theoretical predictions are checked by estimating the following equation:

$$
t_{s t}=\alpha_{s}+\beta_{t}+\gamma_{1} \lambda h_{s t}+\gamma_{2}(1-\lambda) h_{s t}+\gamma_{3}(1-\psi) h_{s t}+\gamma_{4} \lambda(1-\psi) h_{s t}+\delta_{2} x_{s t}+\epsilon_{s t}
$$

where $t_{s t}$ is the tax rate for province $s$ and year $t ; \alpha_{s}$ are province-fixed effects; $\beta_{t}$ are dummies that capture macro-shocks and common changes in fiscal policy; $h_{s t}$ is the average tax rate of the neighboring provinces in year $t$. Moreover $\psi$ is a dummy for the provinces where $t_{s t}>h_{s t}$ (51 observations for cigarettes and 57 for gasoline); $\lambda$ is a dummy for the provinces where the equalizing system operates (75 observations); $\lambda(1-\psi)$ is a dummy where $t_{s t}<h_{s t}$ and equalization holds including 29 observations for cigarettes and 37 for gasoline; $x_{s t}$ is a vector of province-specific time-varying controls; $\epsilon_{s t}$ is the error term. The vector $x_{s t}$ of controls is composed of 23 variables: ${ }^{13}$ the mean neighboring US tax rate, EXPE $E_{s t}, I N C_{s t}$ and its square, UNEMPst $, G D P_{s t}, P O P_{s t}$, $A G E D_{s t}$ and $D E N S_{s t}$, the neighboring Canadian variables for $I N C_{s t}$ and its square, $G R A N T_{s t}, U N E M P_{s t}, G D P_{s t}, D E N S_{s t}$ and symmetric variables for the neighboring US states, two dummies for the political affiliation of the premier.

Equation (16) can be used to check the reaction function slope for four taxequalization regimes. First $\gamma_{1}$ is the slope of the tax-rate reaction function when $t_{s t}>h_{s t}$ and province $s$ receives the equalization transfer (in the cigarette-tax case 46 observations pick up this regime; in the gasoline case the observations are 38). In Section 4 this corresponds to $\left.\frac{d t_{1}}{d t_{2}}\right|_{t_{1}>t_{2}}$ when $\alpha>0$. The sum $\gamma_{1}+\gamma_{3}+\gamma_{4}$ gives the slope of the tax-rate reaction function in the case $t_{s t}<h_{s t}$ and province $s$ receives the equalization transfer (this case corresponds to 29 observations for cigarette tax and 37 for gasoline). In Section 4 it is $\left.\frac{d t_{1}}{d t_{2}}\right|_{t_{1}<t_{2}}$ when $\alpha>0$. Moreover $\gamma_{2}$ is the slope of the tax-rate reaction function in the case $t_{s t}>h_{s t}$ and province $s$ does not receive the equalization transfer (the observations in this regime are 13 for cigarette and 10 for gasoline). In the theoretical model $\gamma_{2}$ corresponds to $\left.\frac{d t_{1}}{d t_{2}}\right|_{t_{1}>t_{2}}$ when $\alpha=0$. Finally, $\gamma_{2}+\gamma_{3}$ is the slope of the tax-rate reaction function in the case $t_{s t}<h_{s t}$ and province $s$ does not receive the equalization transfer (in this last regime we have 22 observations for cigarettes and 20 for gasoline). In Section 4 this is $\left.\frac{d t_{1}}{d t_{2}}\right|_{t_{1}<t_{2}}$ when $\alpha=0$.

Note that a significant and negative $\gamma_{3}$ tests Hypothesis 2 when $\alpha=0$ :

$$
\left.\left[\left.\frac{d t_{1}}{d t_{2}}\right|_{t_{1}>t_{2}}-\left.\frac{d t_{1}}{d t_{2}}\right|_{t_{1}<t_{2}}\right]\right|_{\alpha=0}>0
$$

\footnotetext{
${ }^{13}$ All variables are extensively defined in table 1.
} 
while a negative and significant $\gamma_{3}+\gamma_{4}$ tests Hypothesis 2 when $\alpha>0$ :

$$
\left.\left[\left.\frac{d t_{1}}{d t_{2}}\right|_{t_{1}>t_{2}}-\left.\frac{d t_{1}}{d t_{2}}\right|_{t_{1}<t_{2}}\right]\right|_{\alpha>0}>0
$$

Finally, a positive and significant $\gamma_{4}$ tests Hypothesis 3:

$$
\left.\left[\left.\frac{d t_{1}}{d t_{2}}\right|_{t_{1}>t_{2}}-\left.\frac{d t_{1}}{d t_{2}}\right|_{t_{1}<t_{2}}\right]\right|_{\alpha>0}<\left.\left[\left.\frac{d t_{1}}{d t_{2}}\right|_{t_{1}>t_{2}}-\left.\frac{d t_{1}}{d t_{2}}\right|_{t_{1}<t_{2}}\right]\right|_{\alpha=0},
$$

which means that the difference in slopes (Hypothesis 2) decreases if the equalization transfer is introduced.

\subsection{Estimation Strategy}

The theoretical model discussed in Section 3 yields two simultaneous equations: one from the solution of the optimal tax problem of province 1, which determines $t_{1}$, for a given $t_{2}$ and the other from the symmetric tax problem solved by province 2 , which determines $t_{2}$, for a given $t_{1}$. In the empirical specification we can conceive $t_{1}$ as the Canadian province tax rate $\left(t_{s t}\right)$ and $t_{2}$ as the mean of the neighboring province tax rates $\left(h_{s t}\right)$. If not all the neighboring variables are used but only the mean, we can reduce the empirical situation to a two-province problem: each province competes with one fictitious (average) neighboring province.

As in all studies of social interaction, this economic framework suffers from an identification problem concerning the model's structural equations and a simultaneity bias in the standard errors of the equation being estimated. These issues arise because tax-rate interactions are symmetric, in the sense that each province's behavior affects that of its neighbors in the same way, while the neighboring provinces behavior affects the province's own behavior, which feeds back again on the neighbors.

We tackle these two problems firstly by identifying one of these two equations, and secondly, by instrumenting the endogenous variables to cope with the endogeneity bias.

We estimated (16) for the cigarette and gasoline tax rates in Canada. Note that the four interactions of the mean Canadian neighboring tax rate are endogenous because they may also be influenced by the Canadian province. The mean neighboring US tax rate (eight out of the ten provinces considered border on the US) is endogenous: the US rate mean may also be influenced by the Canadian province. Moreover, the variable $E X P E_{s t}$ may be influenced by the tax revenue on cigarette or gasoline and therefore be endogenous. We thus finally have six endogenous variables. A simple OLS estimate of (16) would suffer from endogeneity bias: the error term $\epsilon_{s t}$ would be correlated with the error terms of the other simultaneous equations of the system. We use the two-stage least squares 
method: first we estimate the reduced forms of the six endogenous variables and then substitute their fitted values into (16). The residuals of this last equation are corrected by using the actual values of the endogenous variables. ${ }^{14}$

\subsubsection{Instrumentation}

The vector of instruments is composed of 11 variables: ${ }^{15}$ GRANT, INCT AX, PROG$C O N S, L I B E R A L S, L E F T$ and the mean Canadian and US neighboring variables for POP, AGED and INCTAX. We argue that these variables affect $\lambda h_{s t}$, $(1-\lambda) h_{s t},(1-\psi) h_{s t}, \lambda(1-\psi) h_{s t}, E X P E_{s t}$ and the mean neighboring US tax rate, but are not correlated with $t_{s t}$. This vector enabled us to identify equation (16), which has six endogenous variables.

We instrument the mean Canadian neighboring tax rate $\gamma_{1} \lambda h_{s t}, \gamma_{2}(1-\lambda) h_{s t}$, $\gamma_{3}(1-\psi) h_{s t}, \gamma_{4} \lambda(1-\psi) h_{s t}$ with the neighboring Canadian variables for $P O P_{s t}$, $A G E D_{s t}, I N C T A X_{s t}$. The level of taxation, and in a reduced form equation also the tax rate on cigarettes or gasoline, is in fact normally linked to the size of population: these variables influence the available tax base and the cost of public goods. Moreover, age structure influences taxation according to the relative preference for social policies. It is likely that these neighboring variables do not affect the province's tax rate on cigarettes or gasoline. The inclusion of INCTAX explained by the fact that the federal income tax can influence the provincial tax, and therefore provincial taxes on cigarettes, in a reduced form equation (Besley, Rosen, 1998). We instrumented the mean US neighboring state tax rate with the same corresponding variables.

Finally, we instrument EXPE $E_{s t}$ with $G R A N T_{s t}$ and INCTAX $X_{s t}$. Both variables are important in determining the tax rate on cigarettes - not directly, but indirectly through the level of public expenditure. The larger the grant that a province receives, the higher its public expenditure for a given level of taxation. The variable INCTAX $X_{s t}$ is included because the federal income tax may influence the provincial income tax and therefore total provincial revenue, which of course is closely correlated with total expenditure. INCTAX $X_{s t}$ does not work very well as an instrument for the gasoline-tax regression. We included it in the explicative covariates of the second stage regression, in fact gasoline tax has a much larger tax base than cigarette tax and it is likely that each province will decide its level by also considering the federal fiscal pressure (which in our case is measured with $I N C T A X_{s t}$ ) on their citizens: this implies that the structural equation of gasoline tax may be affected by this variable. Finally, since it is likely that public expenditure policies differ according to the political majority, we also

\footnotetext{
${ }^{14}$ The two-stage least square strategy would produce residuals using the fitted values of the endogenous variables. Since we are estimating the structural model, we are interested in the residuals using the actual values of the endogenous variables.

We perform the procedure by using the ivreg command of STATA, which already gives the corrected residuals with the actual values of the endogenous variables.

${ }^{15}$ The variables are extensively defined in table 1.
} 
included the political variables for the relative strengths of the various groups PROG - CONS, LIBERALS and LEFT- as instruments of EXPE $E_{s t}$.

\subsubsection{Controls}

Since $G R A N T_{s t}$ and $I N C T A X_{s t}$ can also proxy time-varying provincial shocks (business cycle), they may give rise to missing variables in the second stage equation. We control for this in the second stage equation by using $U N E M P_{s t}$, $I N C_{s t}$ and its square, and $G D P_{s t}$. The political variables may also influence the choice of the cigarette tax rate; consequently in the second stage equation we control for dummies revealing the political affiliation of the premier which are closely related with the political instruments and therefore capture the same political effect.

We also controlled for $P O P_{s t}, A G E D_{s t}$ and $D E N S_{s t}$, the mean Canadian neighboring and the mean neighboring US corresponding density variable. These neighboring variables may be important when the provinces evaluate the crossborder shopping threat and decide the tax rate.

Spatial error dependence may arise when the error includes some omitted variables not captured in the covariates, which are themselves spatially dependent. If the spatial dependence is ignored the estimation may be biased (Brueckner, 2001; Brueckner and Saavedra, 2001). We deal with this problem by controlling for more than one variable, proxying the neighboring economic environment: the neighboring Canadian variables for $I N C_{s t}$ and its square, $G R A N T_{s t}, U N E M P_{s t}$, $G D P_{s t}$ and symmetric variables for the neighboring US provinces. If those variables are omitted, they may generate a spurious correlation between a province's own tax and the neighboring tax or other exogenous covariates.

We finally controlled for year and province effects. Year effects are especially important in the cigarette case because the strong federal antismoking policy has led the Canadian government to raise the federal tax on cigarettes year after year. This may give rise to a vertical externality linking the provincial tax to the federal tax (Besley, Case, 1998): the year effects control for this link, which may mimic the neighboring tax link.

After performing the two stage least square regressions we test the validity of the instrument, regressing the residuals from the second stage equation on the instruments and all the exogenous variables and running an F-test on the joint significance of the instruments (Sargan test).

An identical procedure was adopted to instrument the endogenous variables with more aggregated estimates of the reaction function slopes.

\subsection{Results}

In Table 2, which refers to cigarette tax, we report the results (col.1) of an OLS regression of cigarette tax rates on the aggregated mean of the neighboring 
Canadian tax-rates. We obtain a positive but not significant coefficient. When we instrument and use the two stage least square method (col.2, table 2), the coefficient becomes significant $(t=2.81)$ and continues to be positive: if the average neighboring province increases its tax rate by 1 , an average Canadian province will increase its own tax rate by 0.778 . The overidentification test is not very robust $(\operatorname{Prob}>F=0.49)$. This first test confirms that there is a significant relationship in Canada between neighboring cigarette taxes, and that the slope of the reaction function is positive (Hypothesis 1).

We then run (column 3, table 2) a regression where we interact the reaction function coefficient with a dummy accounting for the tax regimes $t_{s t}>h_{s t}$ (col. 3 of tab. 2). We find that a province with a higher tax rate than its neighbor does not react differently to a neighboring change in tax than if it has a lower rate: the coefficient is not significant. This means that there is apparently no difference in the reaction function slopes between the two tax regimes $t_{s t}>h_{s t}$ and $t_{s t}<h_{s t}$. In this case too, the overidentification test is not very robust (Prob $>F=0.56$ ), which may mean that the instruments are not very good, or that the specification is not correct because some variable correlated with the instruments is missing. ${ }^{16}$ Our theory suggests why. In fact, if we want to test Hypothesis 2 we must look at the reaction function slopes in the case when no-equalization holds. We therefore use the same instruments but enrich the specification by estimating (16). Note that the difference in slopes between the tax regime $t_{s t}<h_{s t}$ and $t_{s t}>h_{s t}$, when the province receives the equalization transfer is $\gamma_{3}+\gamma_{4}=-2.368+2.220$, and the same difference, when the province does not receive the equalization transfer, is $\gamma_{3}=-2.368$; both coefficients are more than $5 \%$ significant: this is consistent with Hypothesis 2 in Section 5. Finally Hypothesis 3 is confirmed because $\gamma_{4}=2.220>0$ is significant, which means that the difference in slope decreases. ${ }^{17}$

Table 3 reports the same regressions as table 2 for gasoline tax. Column 2 evidences a significant link between the provincial tax and the mean Canadian neighboring tax. Interestingly the overidentification test is very good (Prob > $F=0.96)$. Recall that in the corresponding regression for the cigarette tax, it is 0.46 . This probably means that the specification is correct: in fact, the interactions with the dummies (column 4, table 3) are not significant. This re-

\footnotetext{
${ }^{16}$ The residuals may include this variable, which if related with the instruments will also be reflected in the coefficients of the instruments when we regress the residuals on all the covariates plus the instruments to test the null hypothesis that the instruments are jointly different from 0 . It follows that the test is weakened by the correlation between the instruments and the missing variable included in the residuals.

${ }^{17}$ In the regression of column 4 we drop the regressor $A G E D_{s t}$. If this regressor is left, the values of the tax variables are almost the same, but the significance of the regressors decreases. However the coefficient of $A G E D_{s t}$ in the specification with the neighboring interactions is not significant at all $(t=0.01)$. Nothing changes in the overidentification test $($ Prob $>F=0.99)$ : if there had been a missing variable, the biased residuals would probably have been correlated with two instruments: the corresponding Canadian and US neighboring variables for $A G E D_{s t}$.
} 
sult is consistent with a linear cross-border shopping function (Kanbur and Keen 1993). ${ }^{18}$ In this case the shopping technology does not exibit scale economies: people crossing the border cannot do anything more than fill up. It is not particularly easy to buy fuel and store it, which is the source of the nonlinearity in the cross-border shopping cost.

We tried other specifications for the neighboring variables. Specifically, we used a more constrained neighboring variable like the mean Canadian and US neighboring tax rate, but this did not yield any tax competition result either for cigarettes or gasoline. Interestingly, when we used the "Second-Order Neighbors" (the mean of the neighbors of the neighbors), we obtained no significant tax competition either in the cigarette or in the gasoline case. This strengthens the conclusion that the result is not just due to a correlation among tax rates of all Canadian provinces but is a neighbor's effect.

\section{Conclusions}

We have theoretically assessed the effect of an equalization transfer in a model with tax competition on a mobile good. We have shown that the tax reaction function differs according to whether a province exports or imports the good. An exporting province has a more pronounced slope than an importing one. This result was obtained by assuming a cross-border shopping cost not linear in the distance from the border. The introduction of the equalization transfer offsets such nonlinearity in the tax reaction function.

This result was tested by using a data-set on cigarette and gasoline taxes for Canada and US between 1984 and 1994. The test confirmed the nonlinearity in the cigarette reaction function and showed that the introduction of an equalization transfer reduces the difference in tax competition between the two tax regimes. This is not the case of gasoline: the nonlinearity does not hold in our test and therefore tax competition is not affected by the introduction of the equalization transfer, even though this is theoretically supposed to affect the fiscal externality (Bucovertsky, Smart 2006; Kothenburgen, 2002).

Several extensions of the existing analysis are possible. On theoretical ground it would be important to work on the welfare analysis to understand when offsetting nonlinearities generates a Pareto improvement for the federation. It would be also interesting to model the stage when the federal government decides how to allocate the transfers to the local governments. The equilibrium transfers may be very different according to whether the central government is maximizing a representative federal welfare function or is maximizing its re-election chances. In the latter case the federal government might use transfers to discriminate between political allies and adversary administrations as it happens in the US (Larcinese,

\footnotetext{
${ }^{18}$ It is easy to show that the equalization system does not affect the reaction function slope if the cross-border shopping cost is linear.
} 
Rizzo and Testa, 2006).

On the empirical side, it would be useful to collect data on border densities and border lengths. It is reasonable to assume that each state fixes its tax rate in view of the neighboring rates, where population density near the border and the length of the border are greater. Finally an interesting empirical application to the Canada-US border would be a further check for yardstick competition: should an incumbent governor of a US state or Canadian province worry about national neighbors' policies, or should it also consider international neighbors? Hence, international yardstick competition rises the intriguing question of whether national or international neighbors are more important in determining the behavior of incumbent politicians.

\section{References}

[1] Asplud, M., Friberg R., Wilander F. (2005), Demand and Distance: Evidence on Cross-Border Shopping, CEPR Discussion Papers 4983.

[2] Besley, T. and H. S. Rosen (1998), Vertical externalities in tax setting: evidence from gasoline and cigarettes, Journal of Public Economics 70, 383-398.

[3] Boadway, R. and M. Hayashi (2002), An Empirical Analysis of Intergovernmental Tax Interaction: the Case of Business Income Taxes in Canada, Canadian Journal of Economics, 34, 481-503.

[4] Brueckner, J. K. (2001) Strategic Interaction Among Governments: An Overview of Empirical Studies, mimeo, University of Illinois UrbanaChampaign.

[5] Brueckner, J. and Saavedra, L. A. (2001) Do Local Governments Engage in Strategic Property-Tax Competition?, National Tax Journal, 54, 203-229.

[6] Bucovetsky, S. and M. Smart (2006), The Efficiency Consequences of Local Revenue Equalization: Tax Competition and Tax Distortions, Journal of Public Economic Theory, 8, 119-144.

[7] Commission of the European Communities (1985), Completing the Internal Market, $\mathrm{COM}(85)$ 310, Brussels.

[8] Devereux M., Lockwood B., Redoano M. (2002), Do provinces Compete over Corporate Tax Rates?, CEPR Discussion Papers 3400.

[9] Esteller-Moré A. and A. Solé-Ollé (2002), Tax Setting in a Federal System: The Case of Personal Income Taxation in Canada, International Tax and Public Finance, 9, 235-257. 
[10] Fitz Gerald J., Johnston J., Williams J. (1995), Indirect Tax Distortion in a Europe of Shopkeepers, ESRI working paper n.56, Dublin.

[11] Kanbur, R. and M. Keen, (1993), Jeux sans Frontiers: Tax Competition and Tax Coordination when provinces Differ in Size, American Economic Review, 83, 887-892.

[12] Kothenburger, M. (2002), Tax Competition and Fiscal Equalization, International Tax and Public Finance, 9, 391-408.

[13] Heyndels, B., Vuchelen, J. (1998), Tax Mimicking among Belgian Municipalities, National Tax Journal, 51, 89-101.

[14] Larcinese V., Rizzo L., Testa C. (2006), Allocating the US Federal Budget to the States: the Impact of the President, Journal of Politics 68, 447-456.

[15] Mintz, J. and Tulkens, H. (1986), Commodity Tax Competition between Member provinces of a Federation: Equilibrium and Efficiency, Journal of Public Economics 29, 133-172.

[16] Smart, M. (1998) Taxation and deadweight loss in a system of intergovernmental transfers, Canadian, Journal of Economics, XXXI, n.1.

[17] Scharf, K. A. (1999) Scale Economies in Cross-Border Shopping and Commodity Taxation, International Tax and Public Finance 6, 89-99

[18] Thursby, J.G. and M. C. Thursby (2000), Interstate Cigarette Bootlegging: Extent, Revenue Losses, and Effects of Federal Intervention, National Tax Journal 53, 59-78.

[19] Zodrow, G. and P.M. Mieszkowski (1986) Pigou, Tiebout, Property Taxation and Underprovision of Local Public Goods, Journal of Urban Economics 19, 356-370

[20] Wooders, M.H., Zissimos B., Dhillon A. (2002), Tax Competition Reconsidered, Warwick Economic Research Papers, Warwick. 


\section{Data Appendix}

$t_{s t}$ Canadian cigarette tax rate, for province $s$ in year $t$, divided by the Canadian CPI and the Canada-US PPP index; these rates are provided by the Finance departments of the ten considered provinces and are expressed in Canadian dollars per pack of 20 cigarettes. Canadian gasoline tax rate for province $s$ in year $t$, divided by the Canadian CPI and the Canada-US PPP index; these rates are from http://www.taxpayer.com/studies/federal/GasTaxReport2001.pdf, where they are expressed in Canadian dollars per lt. of gasoline.

\subsection{Endogenous variables}

$h_{s t}$ is the mean of the tax rates in year $t$ of the Canadian provinces bordering on province $s$, divided by the Canadian CPI and the Canada-US PPP index.

Mean of the tax rates of the US states bordering on province $s$ in year $t$, divided by the US CPI. The tax rates on cigarettes and gasoline for the United States are taken from http://www.library.unt.edu/gpo/acir/acir.html: cigarette tax rates are expressed in US dollars per pack of 20 cigarettes and gasoline tax rates are expressed in US dollars per gallon of gasoline, then transformed in lt.

$E X P E_{s t}$ is the total province expenditure divided by the GDP for province $s$ in year $t$. Total province expenditure comes from www.statcan.ca.

\subsection{Demographic and economic variables}

$P O P_{s t}$ is the number of persons in province $s$ in year $t$. Figures are taken from www.statcan.ca for Canada and http://www.census.gov for the United provinces.

$D E N S_{s t}$ is calculated as the total population $\left(P O P_{s t}\right)$ divided by the area for province $s$ in year $t$. Areas are expressed in square miles: for Canada from http://www.statcan.ca/english/Pgdb/Land/Geography/phys01.htm and for the US from http://quickfacts.census.gov/qfd/index.html.

$A G E D_{s t}$ is the ratio of individuals aged over 65 to the total population of province $s$ in year $t$. The number of individuals aged over 65 is obtained from http://www.statcan.ca for Canada and www.census.gov for the United provinces.

$U N E M P_{s t}$ unemployment rate for province $s$ in year $t$. From http://www.statcan.ca for Canada and from http://www.stats.bls.gov for the US.

$I N C_{s t}$ per-capita income for province $s$ in year $t$ divided by the Canadian CPI and the Canada-US PPP index for Canada and US CPI for United States. Income figures are obtained from http://www.statcan.ca for Canada and from http://www.bea.doc.gov for the US.

$G R A N T_{s t}$ per-capita federal grant-in-aid for province $s$ in year $t$ divided by the Canadian CPI and the Canada-US PPP index for Canada and US CPI for United States. Federal grant-in-aid for the US is obtained from "Federal Expenditures by State" which is part of the Consolidated Federal Funds Reports 
program from US Census Bureau and for Canada from http://www.statcan.ca.

$G D P_{s t}$ per-capita GDP for province $s$ in year $t$ divided by the Canadian CPI and the Canada-US PPP index for Canada and US CPI for United States. GDP is obtained from http://www.statcan.ca for Canada and http://www.bea.doc.gov for the US.

INCTAX $X_{s t}$ federal tax revenue over GDP for province $s$ in year $t$. Federal tax-revenue figures are from http://www.statcan.ca for Canada and from www.bea.doc.gov for the US.

$P R O G-C O N S_{s t}$ percentage of the Progressive Conservative in the provincial legislature. From http://www.swishweb.com/Politics/Canada.

$L I B E R A L_{s t}$ percentage of the Liberal Party in the provincial legislature. From http://www.swishweb.com/Politics/Canada.

$L E F T_{s t}$ percentage of New Democratic, Quebec and Social Credit parties in the provincial legislature. From http://www.swishweb.com/Politics/Canada.

Also computed are two dichotomous variables to account for the party of the premier (Progressive Conservative and Liberal).

From http://www.swishweb.com/Politics/Canada.

The PPP (Parity Purchasing Power) index for Canada-US is downloaded from the OECD web site.

The US CPI (Consumer Price Index) is taken from the Statistical Abstracts of the United provinces (2000).

The Canadian CPI (Consumer Price Index) is from http://www.statcan.ca.

\subsection{The neighboring variables}

Computed for all the demographic and economic variables are the neighboring Canadian and United provinces variables. A neighboring Canadian variable for province $s$ in year $t$ is computed as the mean of the variable in all the Canadian provinces neighboring province $s$ in year $t$. The neighboring Canadian $x$ variable is defined as: $C N E I G H x$.

A neighboring United States variable for province $s$ in year $t$ is computed as the mean of the variable in all the US states neighboring province $s$ in year $t$. The neighboring United States $x$ variable is defined as: US NEIGH $x$.

An example: suppose there are four neighboring provinces (defined as $n=$ $2,3,4,5)$, then the neighboring Canadian $x_{s t}$ variable for province 1 in year $t$ would be:

$$
C N E I G H x_{1 t}=\frac{\sum_{s \in n} x_{s t}}{4} .
$$




\section{Appendix}

If $t_{1}>t_{2}, \frac{d t_{1}}{d t_{2}}=\frac{1+A\left(t_{1}-\alpha\right)}{2+A\left(t_{1}-\alpha\right)}$. Using the FOC of $(12)$ which gives $t_{1}\left(t_{2}, \alpha\right)$ and taking the derivative of $\frac{d t_{1}}{d t_{2}}$ with respect to $\alpha$, we get:

$$
\frac{d^{2} t_{1}}{d t_{2} d \alpha}=\frac{A\left(\frac{d t_{1}}{d \alpha}-1\right)}{\left[2+A\left(t_{1}-\alpha\right)\right]^{2}},
$$

using $0<\frac{d t_{1}}{d \alpha}<1:^{19}$

$$
\frac{d^{2} t_{1}}{d t_{2} d \alpha}<0 \quad \forall \alpha \in\left[0, \frac{1}{A}[\right.
$$

Note that (17) proves that $\frac{d t_{1}}{d t_{2}}$ is continuous and monotone in $\alpha$. This means that if an equalization transfer is introduced $(\alpha>0)$ the reaction function slope is lower than in the no-equalization case.

If $t_{1}<t_{2}, \frac{d t_{1}}{d t_{2}}=\frac{1-A\left(t_{1}-\alpha\right)}{2-A\left(t_{1}-\alpha\right)}$. Using the FOC of (12) which gives $t_{1}\left(t_{2}, \alpha\right)$ and taking the derivative of $\frac{d t_{1}}{d t_{2}}$ with respect to $\alpha$, we get:

$$
\frac{d^{2} t_{1}}{d t_{2} d \alpha}=\frac{-A\left(\frac{d t_{1}}{d \alpha}-1\right)}{\left[2-A\left(t_{1}-\alpha\right)\right]^{2}}
$$

and using $0<\frac{d t_{1}}{d \alpha}<1$, one obtains:

$$
\frac{d^{2} t_{1}}{d t_{2} d \alpha}>0 \quad \forall \alpha \in\left[0, \frac{1}{A}[\right.
$$

As before, (18) states that $\frac{d t_{1}}{d t_{2}}$ is continuous and monotone in $\alpha$. This proves that if an equalization transfer is introduced $(\alpha>0)$ the reaction function slope is higher than in the no-equalization case.

Let us define:

$$
\Delta=\left.\frac{d t_{1}}{d t_{2}}\right|_{t_{1}<t_{2}}-\left.\frac{d t_{1}}{d t_{2}}\right|_{t_{1}>t_{2}}
$$

and then use (17) and (18):

$$
\frac{d \Delta}{d \alpha}=\left.\frac{d t_{1}}{d t_{2} d \alpha}\right|_{t_{1}<t_{2}}-\left.\frac{d t_{1}}{d t_{2} d \alpha}\right|_{t_{1}>t_{2}}>0 \quad \forall \alpha \in\left[0, \frac{1}{A}[.\right.
$$

Taking account of continuity and monotonicity, we can establish that if an equalization transfer holds, the difference in slope in a point $\left(t_{1}, t_{2}\right)$ belonging to the reaction function in the tax-regime $t_{1}<t_{2}$ and any other point $\left(t_{1}, t_{2}\right)$ belonging to the reaction function in the tax-regime $t_{1}>t_{2}$ decreases in absolute value with respect to the no-equalization case.

The symmetric case is ruled out because, given that $\gamma_{1} \neq \gamma_{2}$, it will never be an equilibrium.

\footnotetext{
${ }^{19}$ This can be shown, by totally differentiating with respect to $t_{1}$ and $\alpha$, the FOC and using Assumptions 1-3.
} 


\begin{tabular}{|c|c|c|c|c|c|}
\hline Variable & Obs & Mean & Std. Dev & Min & Max \\
\hline CTAX (province unit cigarette tax, 1989 US\$) & 110 & 0.81 & 0.30 & 0.22 & 1.53 \\
\hline $\begin{array}{l}\text { C NEIGH CTAX (neighboring Canadian province average unit cigarette tax, } 1989 \\
\text { US\$) }\end{array}$ & 110 & 0.78 & 0.24 & 0.21 & 1.35 \\
\hline US NEIGH CTAX (neighboring US state unit cigarette tax,1989 US\$) & 110 & 0.21 & 0.12 & 0 & 0.39 \\
\hline GTAX (province unit gasoline tax, 1989 US $\$$ ) & 110 & 0.72 & 0.28 & 0 & 1.19 \\
\hline $\begin{array}{l}\text { C NEIGH GTAX (neighboring Canadian province average unit gasoline tax, } 1989 \\
\text { US\$) }\end{array}$ & 110 & 0.72 & 0.27 & 0 & 1.19 \\
\hline US NEIGH GTAX (neighboring US state unit gasoline tax,1989 US\$) & 110 & 0.35 & 0.18 & 0 & 0.59 \\
\hline EXPE (total province public expenditure divided by provincial gdp) & 110 & 0.62 & 0.15 & 0.34 & 0.94 \\
\hline PROG-CONS ( $\%$ of progressives-conservatives in the provincial legislature) & 110 & 0.32 & 0.30 & 0 & 0.95 \\
\hline LIBERALS (\% of liberals in the provincial legislature) & 110 & 0.38 & 0.33 & 0 & 1 \\
\hline $\begin{array}{l}\text { NDP (\%of national democrats, quebec party and socialist party in the provincial } \\
\text { legislature) }\end{array}$ & 110 & 0.27 & 0.31 & 0 & 1 \\
\hline $\mathrm{POP}^{*} 10^{-7}$ (province population) & 110 & 0.27 & 0.31 & 0.01 & 1.08 \\
\hline DENS ${ }^{*} 10^{3}$ (population density: population divided by area) & 110 & 12.79 & 11.29 & 2.49 & 38.20 \\
\hline UNEMP (unemployment rate) & 110 & 11.49 & 3.72 & 5 & 21 \\
\hline AGED (proportion of population over 65) & 110 & 0.11 & 0.02 & 0.07 & 0.14 \\
\hline INC $* 10^{3}$ (province income per capita in 1989 US $\$$ ) & 110 & 13.22 & 1.99 & 9.49 & 17 \\
\hline GRANT ${ }^{*} 10^{3}$ (federal grants divided by provincial population) & 110 & 1.07 & 0.46 & 0.42 & 1.98 \\
\hline INCTAX ${ }^{*} 10^{3}$ (federal income tax divided by provincial gdp) & 110 & 82.5 & 13.13 & 53.79 & 11.12 \\
\hline $\mathrm{GDP}^{*} 10^{-3}$ (provincial gross domestic product per-capita in 1989 US million $\$$ ) & 110 & 13.85 & 3.09 & 9.36 & 25.07 \\
\hline C NEIGH DENS $* 10^{3}$ (neighboring Canadian province average population density) & 110 & 12.51 & 8.21 & 3.98 & 27.48 \\
\hline \multirow{2}{*}{$\begin{array}{l}\text { US NEIGH DENS* } 10^{3} \text { (neighboring US state average population density) } \\
\text { C NEIGH UNEMP (neighboring Canadian province average unemployment rate) }\end{array}$} & 110 & 52.92 & 71.42 & 0 & 230.03 \\
\hline & 110 & 10.93 & 2.45 & 6.25 & 15.5 \\
\hline US NEIGH UNEMP (neighboring US state average unemployment rate) & 110 & 4.82 & 2.67 & 0 & 8.64 \\
\hline $\begin{array}{l}\text { C NEIGH INC*10 } 0^{3} \text { (neighboring Canadian province average population per-capita } \\
\text { income in } 1989 \text { US } \$ \text { ) }\end{array}$ & 110 & 13.41 & 1.39 & 10.08 & 15.90 \\
\hline $\begin{array}{l}\text { US NEIGH INC*1033 (neighboring US state average per-capita income in } 1989 \\
\text { US\$) }\end{array}$ & 110 & 12.72 & 6.55 & 0 & 19.24 \\
\hline $\begin{array}{l}\text { C NEIGH GRANT*10 }{ }^{3} \text { (neighboring Canadian province average federal grant on } \\
\text { provincial gdp) }\end{array}$ & 110 & 1.01 & 0.32 & 0.52 & 1.70 \\
\hline US NEIGH GRANT* $10^{3}$ (neighboring US state average federal grant on state gdp) & 110 & 0.54 & 0.29 & 0 & 0.9 \\
\hline $\begin{array}{l}\text { C NEIGH INCTAX* } 10^{3} \text { (neighboring US state average federal income tax on state } \\
\text { gdp) }\end{array}$ & 110 & 80.63 & 10.37 & 53.78 & 100.84 \\
\hline $\begin{array}{l}\text { US NEIGH INCTAX*10 (neighboring Canadian province average federal income } \\
\text { tax on provincial gdp) }\end{array}$ & 110 & 70.97 & 36.12 & 0 & 104.40 \\
\hline $\begin{array}{l}\text { C NEIGH GDP*1033 (neighboring Canadian province average gdp per-capita in } \\
1989 \text { US million \$) }\end{array}$ & 110 & 14.28 & 2.84 & 10.16 & 25.07 \\
\hline $\begin{array}{l}\text { US NEIGH GDP* } 10^{3} \text { (neighboring US state average gdp per-capita in } 1989 \text { US } \\
\text { million \$) }\end{array}$ & 110 & 14.56 & 7.51 & 0 & 22.28 \\
\hline US NEIGH POP* $10^{-7}$ (neighboring US state average population) & 110 & 0.25 & 0.32 & 0 & 1.11 \\
\hline C NEIGH POP* $10^{-7}$ (neighboring Canadian province average population) & 110 & 0.31 & 0.19 & 0.42 & 0.72 \\
\hline C NEIGH AGED (neighboring US state average proportion of population over 65) & 110 & 0.10 & 0.05 & 0 & 0.14 \\
\hline $\begin{array}{l}\text { US NEIGH AGED (neighboring Canadian province average proportion of } \\
\text { population over } 65 \text { ) }\end{array}$ & 110 & 0.11 & 0.01 & 0.07 & 0.13 \\
\hline
\end{tabular}

Notes: Figures are means, with standard deviations in parenthesis, based on annual data for the years 1984-1994, inclusive, for the following ten Canadian provinces: Alberta, Ontario, British Columbia Saskatchewan, Newfoundland, Prince Edward Island, Nova Scotia, New Brusnweek, Quebec, Manitoba. 
Table 2: Tax competition on cigarette tax rate Dependent variable: province cigarette tax rate (specific unit tax), 1984-1994

\begin{tabular}{|c|c|c|c|c|}
\hline & $(1)$ & $(2)$ & $(3)$ & $(4)$ \\
\hline Dependent variable & CTAX & CTAX & CTAX & CTAX \\
\hline C NEIGH CTAX & $\begin{array}{l}0.470 \\
(1.76)\end{array}$ & $\begin{array}{l}0.778 \\
(2.81)^{*}\end{array}$ & $\begin{array}{l}0.780 \\
(2.50)^{*}\end{array}$ & \\
\hline $\begin{array}{l}\text { Interaction with C NEIGH CTAX of a dummy }=1 \\
\text { when there is equalization }\end{array}$ & & & & $\begin{array}{l}0.814 \\
(1.85)\end{array}$ \\
\hline $\begin{array}{l}\text { Interaction with C NEIGH CTAX of a dummy }=1 \\
\text { when there is no equalization }\end{array}$ & & & & $\begin{array}{l}3.370 \\
(2.62)^{*}\end{array}$ \\
\hline $\begin{array}{l}\text { Interaction with C NEIGH CTAX of a dummy=1 } \\
\text { when CTAX lower than C NEIGH CTAX }\end{array}$ & & & & $\begin{array}{l}-2.368 \\
(2.17)^{*}\end{array}$ \\
\hline $\begin{array}{l}\text { Interaction with C NEIGH CTAX of a dummy=1 } \\
\text { when CTAX lower than C NEIGH CTAX \& } \\
\text { equalization }\end{array}$ & & & & $\begin{array}{l}2.220 \\
(2.16)^{*}\end{array}$ \\
\hline $\begin{array}{l}\text { Interaction with C NEIGH TAX of a dummy=1 } \\
\text { when TAX higher than C NEIGH TAX }\end{array}$ & & & $\begin{array}{l}0.069 \\
(0.33)\end{array}$ & \\
\hline overidentification test (Sargan) & & 0.49 & 0.56 & 0.99 \\
\hline Prob > F on exogenous variables ( $p$-value) & 0.0000 & 0.0000 & 0.0000 & 0.0005 \\
\hline $\begin{array}{l}\text { Prob }>F \text { on neighboring exogenous variables } \\
\text { (p-value) }\end{array}$ & 0.0000 & 0.0000 & 0.0000 & 0.0009 \\
\hline Prob > F on the year effects ( $p$-value) & 0.0000 & 0.0000 & 0.0000 & 0.0004 \\
\hline Prob > F on the province effects ( $p$-value) & 0.0001 & 0.0000 & 0.0007 & 0.0377 \\
\hline Constant & YES & YES & YES & YES \\
\hline Province fixed effect & YES & YES & YES & YES \\
\hline Year fixed effect & YES & YES & YES & YES \\
\hline Observations & 110 & 110 & 110 & 110 \\
\hline R-squared & 0.92 & 0.91 & 0.90 & 0.76 \\
\hline Adjusted R-squared & 0.86 & 0.84 & 0.83 & 0.58 \\
\hline
\end{tabular}

OLS regressions; Robust t statistics in parentheses ( ${ }^{*}$ significant at $5 \%$; ${ }^{* *}$ significant at $1 \%$ ).

Notes: Column (1) presents OLS estimates for the cigarette-tax equation with an aggregated tax-competition coefficient. Column (2) presents two stages least squares estimates of the same equation. Column (3) presents two stages least squares estimates, according to the tax regime the province belongs to. Column (4) gives two stages least squares estimate of equation (16), with interactions accounting for different tax regimes and equalization status. Numbers in parenthesis are t-statistics (with robust standard errors adjusted for clustering by province). Variables are defined in table 1 and described in detail in the data appendix. 
Table 3: Tax competition on gasoline tax rate Dependent variable: province gasoline tax rate (specific unit tax), 1984-1994

\begin{tabular}{|c|c|c|c|c|}
\hline & (1) & $(2)$ & (3) & (4) \\
\hline Dependent variable & GTAX & GTAX & GTAX & GTAX \\
\hline C NEIGH GTAX & $\begin{array}{l}0.316 \\
(4.50)^{\star *}\end{array}$ & $\begin{array}{l}0.534 \\
(2.11)^{*}\end{array}$ & $\begin{array}{l}0.592 \\
(1.90)\end{array}$ & \\
\hline $\begin{array}{l}\text { Interaction with C NEIGH GTAX of a dummy=1 } \\
\text { when there is equalization }\end{array}$ & & & & $\begin{array}{l}0.410 \\
(0.49)\end{array}$ \\
\hline $\begin{array}{l}\text { Interaction with C NEIGH GTAX of a dummy=1 } \\
\text { when there is no equalization }\end{array}$ & & & & $\begin{array}{l}0.571 \\
(1.31)\end{array}$ \\
\hline $\begin{array}{l}\text { Interaction with C NEIGH GTAX of a dummy=1 } \\
\text { when GTAX lower than C NEIGH GTAX }\end{array}$ & & & & $\begin{array}{l}0.571 \\
(1.00)\end{array}$ \\
\hline $\begin{array}{l}\text { Interaction with C NEIGH GTAX of a dummy=1 } \\
\text { when GTAX lower than C NEIGH GTAX \& } \\
\text { equalization }\end{array}$ & & & & $\begin{array}{r}-0.251 \\
(0.54)\end{array}$ \\
\hline $\begin{array}{l}\text { Interaction with C NEIGH TAX of a dummy=1 } \\
\text { when GTAX higher than C NEIGH GTAX }\end{array}$ & & & $\begin{array}{l}-0.175 \\
(0.36)\end{array}$ & \\
\hline overidentification test (Sargan) & & 0.96 & 0.96 & 0.99 \\
\hline Prob > F on exogenous variables ( $\mathrm{p}$-value) & 0.0014 & 0.0000 & 0.0000 & 0.1356 \\
\hline $\begin{array}{l}\text { Prob > F on neighboring exogenous variables } \\
\text { (p-value) }\end{array}$ & 0.0000 & 0.0000 & 0.0000 & 0.0055 \\
\hline Prob > F on year effets ( $p$-value) & 0.0639 & 0.035 & 0.2098 & 0.0093 \\
\hline Prob > F on province effects ( $p$-value) & 0.0000 & 0.0000 & 0.0007 & 0.0000 \\
\hline Constant & YES & YES & YES & YES \\
\hline Province fixed effect & YES & YES & YES & YES \\
\hline Year fixed effect & YES & YES & YES & YES \\
\hline Observations & 110 & 110 & 110 & 110 \\
\hline R-squared & 0.96 & 0.93 & 0.93 & 0.91 \\
\hline Adjusted R-squared & 0.93 & 0.87 & 0.88 & 0.84 \\
\hline
\end{tabular}

OLS regressions; Robust t statistics in parentheses ( ${ }^{*}$ significant at $5 \%$; ** significant at $\left.1 \%\right)$.

Notes: Column (1) presents OLS estimates for the gasoline-tax equation with an aggregated tax-competition coefficient. Column (2) presents two stages least squares estimates of the same equation. Column (3) presents two stages least squares estimates, according to the tax regime the province belongs to. Column (4) gives two stages least squares estimate of equation (16), with interactions accounting for different tax regimes and equalization status. Numbers in parenthesis are t-statistics (with robust standard errors adjusted for clustering by province). Variables are defined in table 1 and described in detail in the data appendix. 


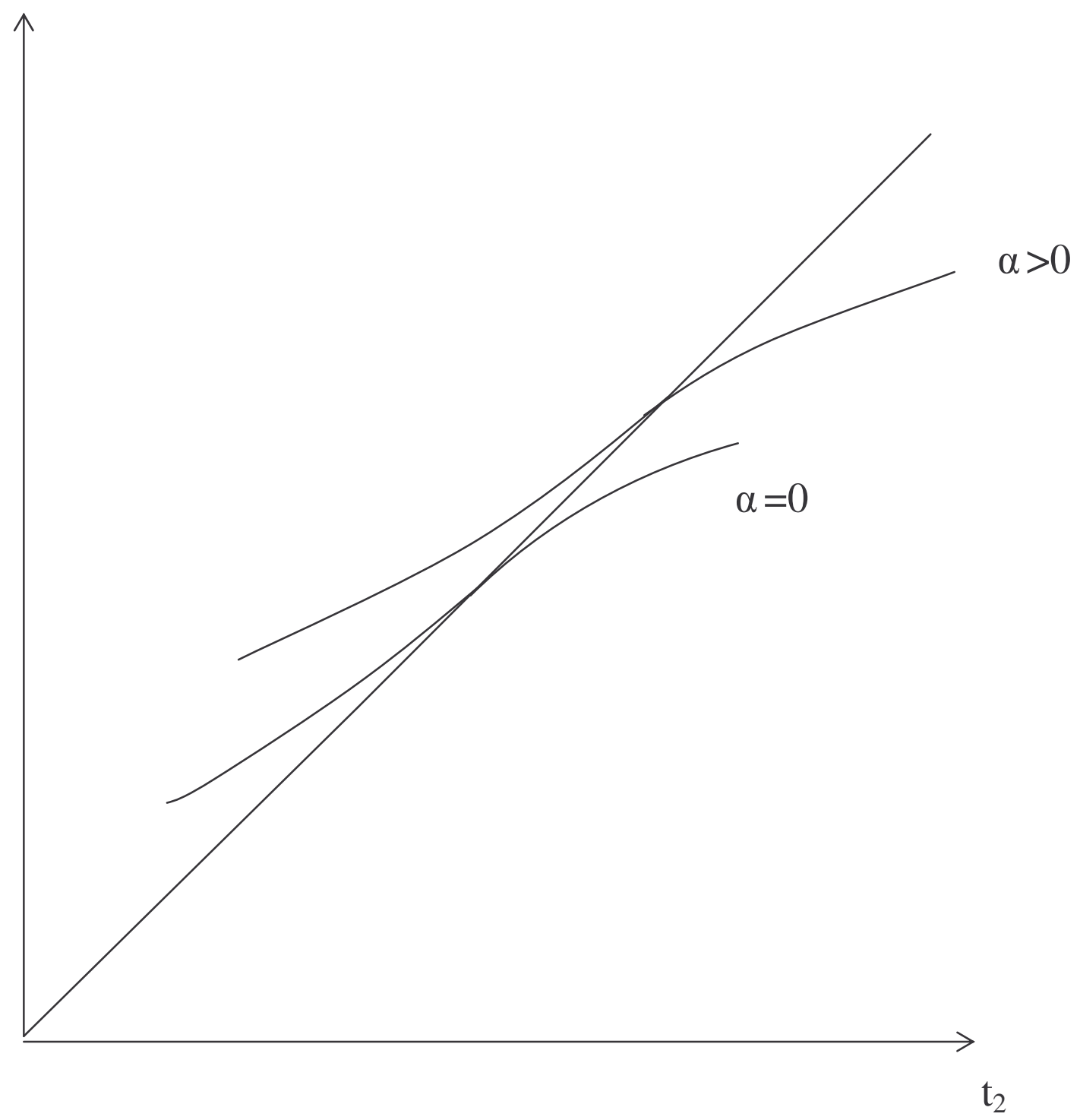

FIG.1 The reaction function, is continuous and convex when $t_{1}>t_{2}$ and concave when $t_{1}<t_{2}$. (the proof is available upon request). The slope is always positive. When an equalization transfer is introduced the reaction function crosses the $45^{\circ}$ line at the point $(t=s+\alpha, t=s+\alpha)$. $(s, s)$ is the point where the reaction function crosses the $45^{\circ}$ line before the introduction of the transfer. the slope of the reaction function, when $t_{1}>t_{2}$ is always higher than when $t_{1}<t_{2}$; finally when the equalization transfer is introduced $(\alpha>0)$ the slope of the reaction function, decreases when $t_{1}>t_{2}$ and decreases when $t_{1}<t_{2}$. 